\title{
Sistema contábil para gestão da ecoeficiência empresarial
}

\section{Accounting system for company eco-efficiency management}

Cassio Luiz Vellani ${ }^{1}$

Professor Mestre dos Departamentos de Ciências Contábeis e Administração da Faculdade Interativa COC da Universidade de Ribeirão Preto

- E-mail: empresaecologica@yahoo.com.br

Maísa de Souza Ribeiro ${ }^{1}$

Professora Doutora do Departamento de Contabilidade da Faculdade de Economia, Administração e Contabilidade de Ribeirão Preto da Universidade de São Paulo • E-mail: maisorib@usp.br

Recebido em $28.07 .2007 \cdot$ Aceito em $15.03 .2008 \cdot 2^{a}$ versão aceita em.09.04.2008

\section{RESUMO}

Desenvolvimento Sustentável, Responsabilidade Social Corporativa e Sustentabilidade Empresarial são conceitos que convergem para o mesmo objetivo: integrar os aspectos econômicos, sociais e ecológicos dos negócios. Muitas empresas mantêm ações que visam à proteção ambiental. No entanto, para contribuir para a sustentabilidade do negócio essas atividades devem convergir para a ecoeficiência. Para isso, a ação ecológica empresarial deve atuar sobre os resíduos emitidos pelas operações da própria empresa e os gastos nelas incorridos devem resultar em benefícios econômico-financeiros ao negócio. Nesse contexto, este artigo identifica a seguinte pergunta de pesquisa: em termos contábeis, como podem ser categorizadas as ações ecológicas empresariais para fornecer informações sobre eventos relacionados com a ecoeficiência do negócio? Procura-se responder a essa pergunta por meio de uma Pesquisa Estudo (holístico) de Casos Múltiplos (tipo 3) e com a seguinte proposição: as ações ecológicas empresariais (AEE) foram classificadas de acordo com suas finalidades, ou seja, tratamento de resíduos próprios, decorrentes de ações internas e ações decorrentes de eventos externos como a preservação de áreas verdes, recuperação de áreas contaminadas, programas de educação ambiental da comunidade externa. Dessa forma, o gestor poderá ter condições para verificar a ecoeficiência do processo operacional propriamente (AEE internas) e os aspectos relacionados à gestão ambiental global (AEE internas e externas). São analisados três tipos de materiais e identificam-se 608 exemplos de ações ecológicas mantidas por 181 empresas. A pesquisa empírica deste artigo revela que a proposta está alinhada com a prática e resulta num sistema contábil para a gestão da ecoeficiência das empresas.

Palavras-chaves: Sustentabilidade Empresarial. Ecoeficiência. Contabilidade da Gestão Ambiental. Pesquisa Estudo de Caso.

\section{ABSTRACT}

Sustainable Development, Corporate Social Responsibility and Corporate Sustainability are concepts that converge towards the same objective: to integrate economic, social and ecological aspects of business. Many companies maintain actions aimed at environmental protection. To contribute to corporate sustainability, however, these activities should converge to eco-efficiency. Therefore, the company's ecological activities should act on the waste produced by company operations and the incurred expenses should result in economic-financial

1 Os autores agradecem ao professor Dr. Sílvio Hiroshi Nakao por disponibilizar tempo e paciência para discutir as idéias iniciais deste artigo. 
benefits for the business. In this context, this article identifies the following research question: in accounting terms, how can the company's ecological actions be categorized to provide information on events related to the eco-efficiency of the business? Attempts are made to answer this question through a (holistic) Multiple Case study (type 3), with the following goal: corporate ecological actions (AEE) were classified according to their objectives, that is, treatment of own waste, deriving from internal actions; and actions resulting from external events, such as the preservation of green areas, recovery of contaminated areas, environmental education programs aimed at the external community. This can allow managers to verify the eco-efficiency of the operating process itself (internal AEE) and the aspect related to global environmental management (internal and external AEE). Three types of material are analyzed and 608 examples of ecological actions are identified, performed by 181 companies. The empirical research reported in this article reveals that the proposal is in line with practice and results in an accounting system to manage companies' eco-efficiency.

Keywords: Corporate Sustainability. Eco-efficiency. Environmental Management Accounting. Case Study Research.

\section{INTRODUÇÃO}

Os conceitos Responsabilidade Social Corporativa" e "Sustentabilidade Empresarial" convergem para o mesmo objetivo: integrar os aspectos econômicos, sociais ecológicos dos negócios. De acordo com o Gvces (2006) e a Sustainable Measures (2006), essa integração pode tornar um negócio sustentável. Ao mesmo tempo em que a empresa proporciona valor aos seus acionistas, também, pode fornecer educação, cultura, lazer e justiça social à comunidade e, ainda, não prejudicar a diversidade e vida dos ecossistemas.

Perrini, Pogutz e Tecanti (2006) investigam a inserção do conceito Responsabilidade Social Corporativa no mundo dos negócios. Lodhia (1999), Ferreira (2004), Velasco, Moori Popadiuk (2001), Vellani, Nakao e Ribeiro (2004), Souza e Ribeiro (2004) abordam somente a dimensão ambiental da sustentabilidade empresarial e investigam a contabilidade da gestão ambiental de determinadas empresas.

Porter e Van der Linde (1995a) e Porter e Van der Linde (1995b), Rogers e Kristof (2003), Vellani e Nakao (2003) identificaram empresas que investiram na proteção do meio ambiente e reduziram gastos. Outros autores como Georgina, Thomas J Jr (1994), Stanko et al. (2006), Martin (2007) escrevem sobre passivo ambiental. Marshall e Brown (2003) e
Raar (2002) escrevem sobre evidenciação da sustentabilidade. Belkaoui (1976), Al-Tuwaijri, Christensen e Hughes II (2003), Bramer, Brooks e Pavelin (2006) investigam a relação entre desempenho ambiental, desempenho econômico e evidenciação ambiental.

Este artigo relaciona Contabilidade e Sustentabilidade, como Burritt (2002), Burritt (2004), Burritt e Saka (2005), Vellani, Nakao e Ribeiro (2004) e Vellani e Ribeiro (2006). Focam-se na contabilidade das atividades mantidas por empresas com finalidades relacionadas com a proteção do meio ambiente. São chamadas, neste artigo, de "ações ecológicas empresariais (ou atividades ambientais)" e os gastos nelas incorridos de "gastos ambientais".

Uma ação ecológica empresarial (ou atividade ambiental) representa um conjunto de tarefas correlatas e inter-relacionadas com uma finalidade comum e específica de proteção dos ecossistemas. Programas que visam ao tratamento do efluente; a reciclagem de resíduos permitindo seu reuso ou sua venda; o aumento da eficiência no uso de insumos; a obtenção de certificações; educação ambiental; preservação e recuperação dos ecossistemas são exemplos de ações ecológicas empresariais.

Os Programas Ambientais são constituídos por um conjunto de atividades e recur- 
sos destinados à realização de determinado objetivo relacionado com a proteção do meio ambiente e podem atuar sobre os resíduos emitidos pela própria empresa durante o processamento de seus produtos e serviços ou sobre outros elementos. Por exemplo, gastos podem ser incorridos para transformar resíduos em insumo ou em produto, neutralizar o efeito tóxico dos resíduos, promover a coleta seletiva de lixo ou reduzir a emissão de resíduos.

Já programas de educação ambiental direcionados à comunidade têm a função de desenvolver a capacidade intelectual do ser humano sobre a importância e modo de proteger os ecossistemas. Apesar de serem importantes para a disseminação de conceitos e atitudes que contribuem para o desenvolvimento sustentável da sociedade, com elas a empresa não anula ou reduz o efeito tóxico dos resíduos emitidos durante o processamento de seus produtos e serviços.

Empresas que não mantêm ações para atuar sobre seus próprios resíduos não são capazes de integrar desempenho ecológico e econômico. Sustentabilidade pode ser alcançada quando há, concomitantemente, desempenho econômico, social e ecológico. Assim, uma ação ecológica somente aumenta a sustentabilidade quando integra desempenho econômico e ecológico. Essa integração chama-se ecoeficiência.

Segundo May, Lustosa e Vinha (2003), o termo Ecoeficiência é o que melhor traduz a meta de integrar eficiência econômica e ecológica. Hoh, Schoer e Seibel (2002) escrevem sobre indicadores de ecoeficiência para o país Alemanha. Este trabalho aborda a ecoeficiência das empresas. Esse conceito busca, ao mesmo tempo, reduzir os custos empresariais e eliminar, durante todo o processamento dos produtos e serviços, o impacto negativo das operações empresariais nos ecossistemas. Saling (2002) descreve a aplicação desse conceito em uma empresa.
Para o WBCSD (1996), a ecoeficiência é alcançada quando uma empresa, por meio do fornecimento de bens e serviços a preços competitivos, consegue satisfazer às necessidades humanas, trazer qualidade de vida, reduzir progressivamente o impacto ambiental e o consumo de recursos ao longo de suas operações, a um nível, no máximo, equivalente à capacidade de sustentação estimada da Terra.

A ecoeficiência significa integrar desempenho econômico e ecológico. Para isso, os gastos incorridos nas atividades ambientais devem gerar benefício econômico-financeiro (desempenho econômico) e a finalidade dessas ações deve ser atuar sobre os resíduos emitidos pela própria empresa durante o processamento de seus produtos e serviços (desempenho ambiental da própria empresa).

Ecoeficiência expressa a competência da empresa em operar sem contaminar o meio ambiente e consumir recursos naturais conforme a capacidade de sustentação dos ecossistemas. Negócio ecoeficiente reduz o desperdício e obtém mais lucros. De acordo com Schmidheiny (1996) e Helminen (2000), ecoeficiência significa um processo que direciona os investimentos e o desenvolvimento de tecnologias para gerar valor ao acionista, minimizar o consumo de recursos e eliminar o desperdício e a poluição.

O alcance da ecoeficiência depende, então, da finalidade da ação ecológica e do resultado econômico-financeiro-ambientaloperacional dos gastos ambientais. Este trabalho não analisa se os gastos incorridos nas ações ecológicas empresariais geram benefício econômico-financeiro ao negócio. $\mathrm{Na}$ verdade, sugere-se que essa etapa seja elaborada por futuros estudos. Neste artigo, são analisadas as finalidades das ações ecológicas empresariais. 


\section{O PROBLEMA}

Na busca por sustentabilidade as empresas podem observar quais ações ecológicas são capazes de tornar seus negócios mais ecoeficientes. Para isso, a Contabilidade deve estar estruturada para fornecer informações sobre o fluxo físico e monetário envolvidos com as entradas e saídas do sistema empresa e o efeito da manutenção de ações ecológicas sobre esses fluxos. Essas informações são relevantes para gerenciar as atividades ambientais e a ecoeficiência empresarial.

Com o intuito de organizar as informações contábeis relacionadas com a gestão ambiental, o problema de pesquisa deste artigo se resume no seguinte questionamento:

Em termos contábeis, como podem ser categorizadas as ações ecológicas empresariais para fornecer informações sobre eventos relacionados com a ecoeficiência do negócio?

Para respondera essa pergunta, normalmente, o pesquisador elabora o Objetivo que, segundo Richardson (1999), define o que se busca com a execução da pesquisa. No entanto, em pesquisas que utilizam a estratégia Estudo de Caso não são apropriadas formulações de objetivos e hipóteses. A própria dinâmica dessa estratégia de pesquisa e o interesse em analisar a proposição admitida orienta o pesquisador na definição do que se busca com a execução da pesquisa (MARTINS, 2006) (YIN, 2005).

\section{ESTRATÉGIA DE PESQUISA}

Em Pesquisa Estudo de Caso, a metodologia pode ser interpretada como o caminho percorrido pelo pesquisador para testar a proposição do estudo. Conforme Yin (2005, p. 44), a estratégia de estudo de caso permite uma investigação de processos organizacionais e administrativos em um ou mais contextos. Esses programas organizacionais e administrativos podem ter finalidades e serem alvos de estudos em Contabilidade, pois investimentos e gastos são incorridos pelas empresas para mantê-los em funcionamento.

As ações ecológicas são exemplos de processos organizacionais e administrativos mantidos por empresas com o intuito de proteger o meio ambiente (ações empresariais com a finalidade relacionada à ecologia). Então, os "casos múltiplos", nesse estudo, são as ações ecológicas empresariais e a unidade única de análise, suas finalidades. Assim, po- de-se chamar esta Pesquisa Estudo de Caso como "pesquisa estudo (holístico) de casos múltiplos (Tipo 3)", pois examina apenas a natureza global de um programa por meio de vários casos (YIN, 2005).

Para Richardson (1999), o pesquisador deve ter bem definido o que busca e ser objetivo na coleta de dados. Coletam-se os dados sobre a finalidade da ação ecológica na descrição dos projetos empresariais de proteção do meio ambiente por meio da Análise de Conteúdo. Segundo Collins e Hussey (2005), essa pode ser uma ferramenta de diagnóstico empregada por pesquisadores em pesquisa qualitativa para converter, sistematicamente, textos em variáveis numéricas. Este trabalho visa identificar, nos materiais abordados, as finalidades das ações ecológicas empresariais e enquadrá-las na proposição desta Pesquisa Estudo de Caso.

\section{A PROPOSIÇÃO}

Segundo Yin (2005, p. 42) e Martins (2006, p. 68), as proposições servem para orientar a
Pesquisa Estudo de Caso. Permitem a correta direção para o seu desenvolvimento. Indica o 
que deve ser pesquisado dentro do escopo do estudo. Nesse sentido, as proposições podem ser entendidas como uma teoria preliminar criada pelo autor para ser, no decorrer da pesquisa, demonstrada e defendida.

A proposição é elaborada com base nos seguintes conceitos e práticas:

- UN (2001) ou ONU (2001): esses dois trabalhos são versões inglês e português de um trabalho das Nações Unidas sobre Contabilidade da Gestão Ambiental. Segundo esse trabalho, os recursos (inputs) injetados no sistema empresa são liberados em forma de produtos (outputs), serviços (outputs) e resíduos (outputs não-produtos). Em seu exemplo, há entradas (inputs) de $100 \mathrm{~kg}$ de material no sistema empresa. Esse material é transformado nas seguintes saídas (outputs e outputs nãoprodutos): $12 \mathrm{~kg}$ de produto (output); $29 \mathrm{~kg}$ de emissões gasosas (output nãoproduto); $43 \mathrm{~kg}$ de resíduos sólidos (output não-produto) e $16 \mathrm{~kg}$ de águas residuais (output não-produto), ou seja, a empresa utilizou $100 \mathrm{~kg}$ de material (inputs) para produzir $12 \mathrm{~kg}$ de produto (outputs) e $88 \mathrm{~kg}$ de resíduos (outputs não-produto). Financeiramente, os recursos consumidos custaram 1000 $€$. Desse total de recursos somente 390 $€$ saem na forma de produtos. O restante $610 €$ pode representar perdas se não forem revertidos em novos inputs, em novos outputs ou repassados ao preço de venda do produto. Portanto, resíduo é desperdício de material e dinheiro.

- Valle (2000); Vellani e Ribeiro (2006): há estudos que expõem soluções para os resíduos das empresas. Valle (2000) propõe abordagens distintas observadas de quatros ângulos: 1. Minimizar: abordagem preventiva, orientada para reduzir o volume e o impacto causado pelos resíduos. Em casos excepcionais, pode-se eliminar completamente a ge- ração de resíduo; 2. Valorizar: abordagem orientada para extrair valores materiais ou energéticos que contribuem para reduzir custos de destinação dos resíduos ou gerar receitas superiores a esses custos; 3. Reaproveitar: abordagem corretiva, orientada para trazer de volta ao ciclo produtivo matérias-primas, substâncias e produtos extraídos dos resíduos. Há três formas distintas para reaproveitar: reciclagem, recuperação (ou reutilização) e reuso. Reciclagem quando há reaproveitamento cíclico de matérias-primas de fácil purificação, como, por exemplo, papel, vidro, alumínio etc. Recuperação no caso de extração de algumas substâncias dos resíduos, como, por exemplo, óxidos, metais etc. Reutilização ou reuso quando o reaproveitamento é direto, sob a forma de um produto, tal como as garrafas retornáveis e certas embalagens reaproveitáveis; 4. Dispor: abordagem passiva, orientada para conter os efeitos dos resíduos, mantendo-os em locais monitorados.

De forma semelhante, Vellani e Ribeiro (2006) e Vellani (2008) contemplam que a empresa, para gerenciar seus resíduos, pode atuar em quatro momentos durante o processamento de seus serviços e produtos: 1. Reduzir o uso de insumos e redução de desperdício; 2. Transformar resíduo em insumos; 3. Transformar resíduos em produtos: as empresas podem transformar o detrito em produto por meio dos processos de reciclagem e recuperação para transformar elemento com potencial poluidor em produtos que podem ser vendidos ou doados; 4. Neutralizar o efeito tóxico dos resíduos: a empresa pode neutralizar o efeito tóxico do resíduo por meio do processo de recuperação de áreas degradadas, instalação de estação de tratamento de efluentes, chaminés etc. 
O alcance da ecoeficiência depende de dois fatores: da finalidade da ação ecológica e do resultado econômico-financeiro dos gastos ambientais. $\mathrm{O}$ sistema contábil interessado em fornecer informações sobre a ecoeficiência do negócio deve se estruturar para captar esses dois fatores. O subsistema da Contabilidade responsável por coletar, registrar, acumular e informar sobre os eventos relacionados com a ecoeficiência pode ser chamado, conforme Ribeiro (2005) e Raupp (2002), de Contabilidade Ambiental (Environmental Accounting) ou segundo Gibson e Martin (2004) e Burritt e Saka (2005) de Contabilidade da Gestão Ambiental (Environmental Management Accounting).

- Burritt e Saka (2005): segundo esses pesquisadores há a Contabilidade Física da Gestão Ambiental que identifica e registra o fluxo físico dos Inputs, $\mathrm{Ou}$ tputs e Outputs não-produtos durante as operações da empresa; e a Contabilidade Monetária da Gestão Ambiental que registra e evidencia os resultados econômico-financeiros das ações ecológicas. Visualizam-se um fluxo monetário e outro físico correspondente aos
Inputs, Outputs e Outputs não-produtos envolvidos com o processo produtivo da companhia. As ilustrações representam uma aplicação da contabilidade da gestão ambiental.

Segundo a COPESUL (2004), os resíduos reciclados são os resíduos separados na central de triagem e destinados a processos externos à empresa. Os recuperados compreendem aqueles aproveitados internamente. $\mathrm{O}$ principal resíduo aproveitado é a borra oleosa. Recolhida nos separadores água-óleo ela é encaminhada como combustível para queima nas caldeiras. Note-se que a empresa transforma um resíduo em insumo, pois gera energia para uso interno a partir de um detrito.

De acordo com o Gráfico $1 \mathbf{0}$, a COPESUL implantou a coleta seletiva em 1989. A partir de 2002, a empresa destina seus resíduos mais para suas operações internas do que a processos produtivos externos. Com isso, consegue aumentar os benefícios econômicofinanceiros com a manutenção de ações ecológicas que visam a transformar resíduos em insumos. O Gráfico $2 \oslash$ demonstra os ganhos causados pela manutenção de ações ecológicas pela COPESUL.

Observe-se que quanto mais a COPESUL destina seus resíduos para uso interno mais

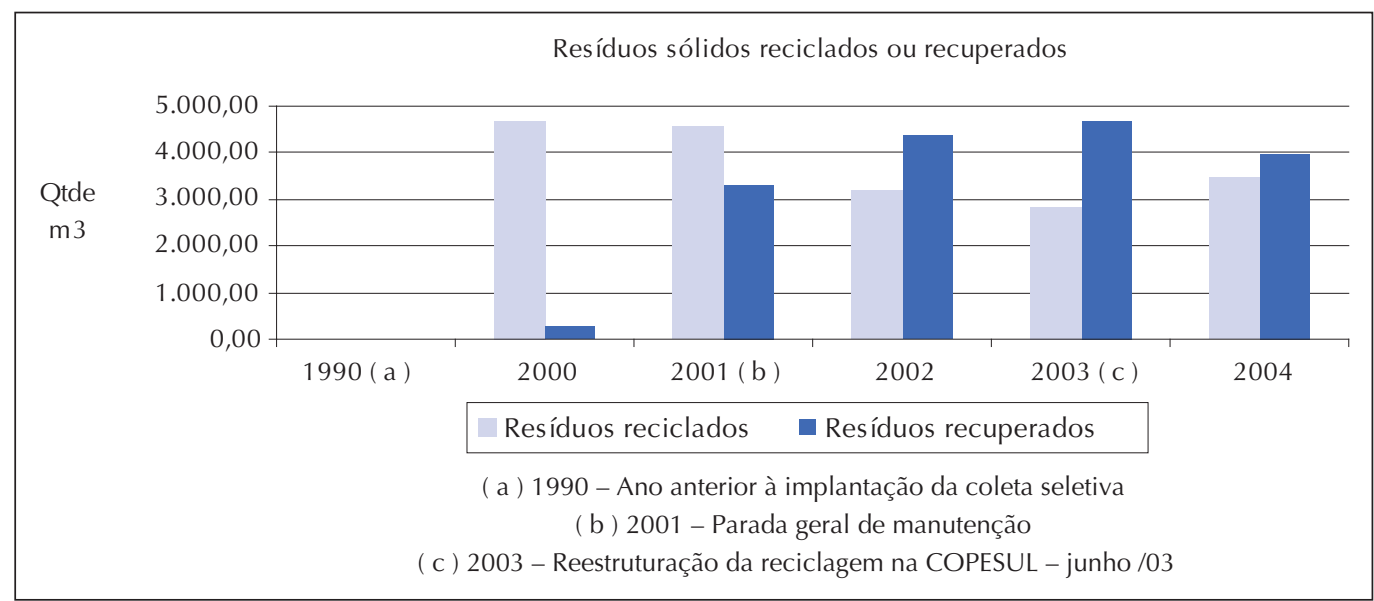

Fonte: Adaptado da COPESUL (2004)

Gráfico 1 Exemplo de indicador físico 


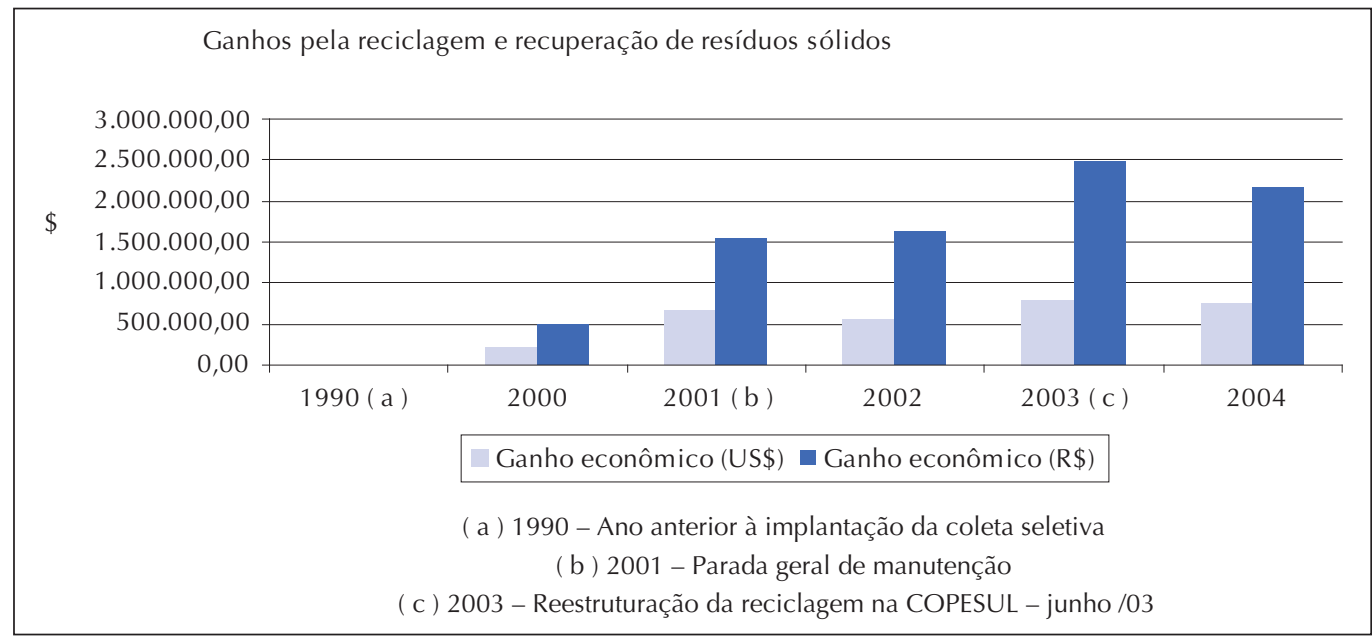

Fonte: Adaptado da COPESUL (2004)

Gráfico 2 Exemplo de indicador monetário

aufere ganhos econômico-financeiros. No Gráfico 1, há indicadores ambientais físicos do processo de reciclagem dos resíduos sólidos da empresa COPESUL e o Gráfico 2 evidencia o ganho econômico por manter ações ecológicas que atuam sobre esses resíduos com a finalidade transformá-los em resíduos.

Note-se, portanto, o uso de indicadores físicos (Gráfico 1) e monetários (Gráfico 2) ambos provenientes do mesmo evento, gerenciamento de resíduos da COPESUL entre 1990 a 2004. Essas duas ilustrações demonstram que a Contabilidade pode fornecer informações sobre atividades ambientais por meio da divulgação de indicadores físicos e monetários. Indicadores físicos e monetários podem ser elaborados e informar sobre a ecoeficiência da empresa.

Almeida (2002) explica que os indicadores ambientais podem servir de parâmetro para as empresas gerenciarem seu desempenho ambiental e defende que podem ser utilizados para medir os avanços na ecoeficiência do negócio. Os indicadores ambientais físicos e monetários divulgam informações úteis e relevantes sobre a atuação ecológica da empresa e seus esforços para promover a ecoeficiência. São os principais instrumentos de medida para as empresas avaliarem a relação de suas operações com os ecossistemas.

Indicadores ambientais servem para prover os executivos da gestão ambiental de informações úteis para tomadas de decisões. Podem indicar se as metas estabelecidas são alcançadas, presença de situações de nãoconformidade, possíveis soluções para os problemas ecológicos, além da consequência econômico-financeira do gerenciamento ambiental. Podem ser utilizados internamente na gestão ambiental e externamente para divulgar os gastos e resultados envolvidos com a proteção do meio ambiente.

Com base em todos os conceitos retroexpostos a proposição é elaborada (Figura 1).

De acordo com a Figura $1 \Theta$, a proposição pode ser descrita da seguinte forma:

As ações ecológicas empresariais (AEE) podem ser categorizadas conforme suas finalidades. Há aquelas que atuam sobre os resíduos emitidos pela própria empresa durante o processamento de seus produtos e serviços. A segunda categoria contém as ações ecológicas de atuação externa à empresa e ao processo operacional corrente como: preservação de áreas verdes, recuperação de áreas contaminadas, programas de educação ambiental direcionados à comuni- 


\section{AÇÕES ECOLÓGICAS EMPRESARIAIS}

\section{AEE Internas}

- Atuar sobre os próprios resíduos

(Forma direta de resgatar a harmonia)

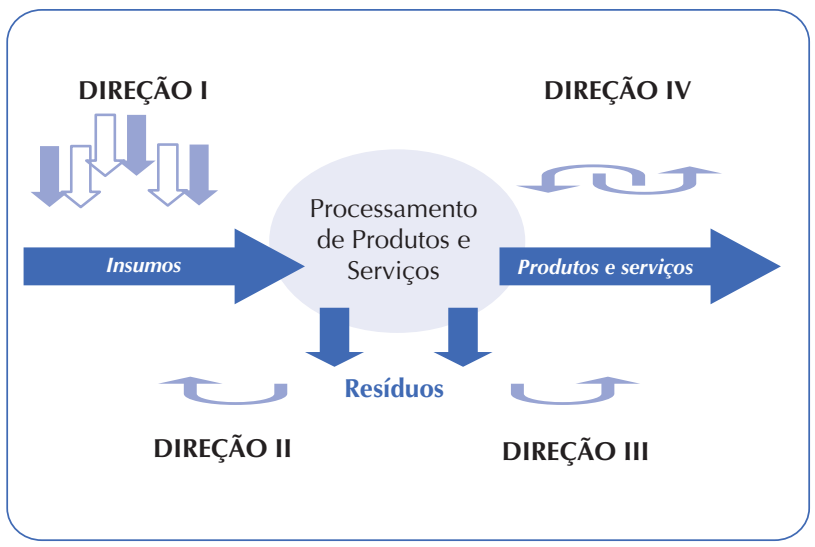

AEE Externas

- Atuar sobre outros elementos

Forma indireta de resgatar a harmonia)

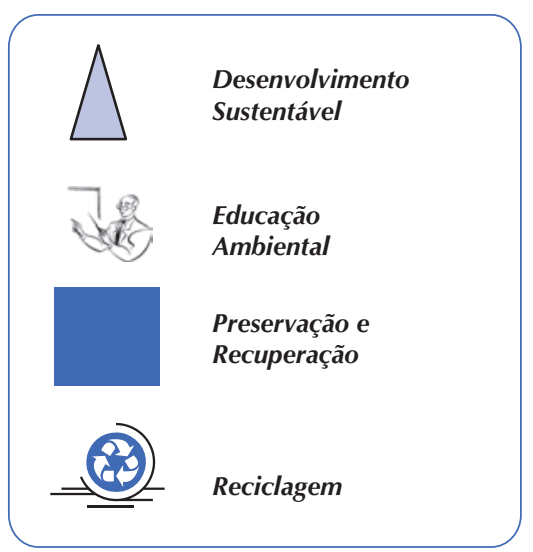

Figura 1

Categorização das ações ecológicas empresariais

dade externa, entre outros. Segregar a informação dessa forma permite ao gestor conhecer a ecoeficiência do processo operacional em si (AEE internas) e a gestão ambiental da empresa como um todo (AEE internas e externas).

Este artigo identifica as ações ecológicas empresariais e com base em suas finalidades as enquadra em duas categorias: ações ecológicas que atuam sobre os resíduos emitidos pela própria empresa durante o processamento de seus produtos e serviços (forma direta de resgatar a harmonia entre os elementos que formam os ecossistemas) e ações ecológicas que atuam sobre outros elementos não relacionados com os resíduos emitidos pela própria empresa durante o processamento de seus produtos e serviços (forma indireta de resgatar a harmonia entre os elementos que formam os ecossistemas).

As finalidades das ações enquadradas na categoria atuar sobre os resíduos emitidos pela própria empresa durante o processamento de seus produtos e serviços representam a forma direta de resgatar a harmonia entre os elementos do meio ambiente e, por isso, podem aumentar a ecoeficiência do negócio. Essas ações podem agir em quatro direções durante o processo produtivo.

Na Direção I, encontram-se duas finalidades: substituir insumos não-renováveis por renováveis, reciclados ou retirados de forma ecológica e reduzir o uso de insumo. A finalidade da ação ecológica, na Direção II, é transformar resíduos em insumos. Na direção III, a ação serve para transformar resíduos em produtos. Por último, as empresas podem manter ações ecológicas, na Direção IV, para reduzirem a emissão de resíduos, cumprirem responsabilidades contratuais, neutralizarem o efeito tóxico do resíduo e coletarem de forma seletiva o lixo.

As ações da categoria atuar sobre elementos não relacionados com os resíduos emitidos pela própria empresa durante o processamento de seus produtos e serviços agem de forma indireta para resgatar harmonia entre os elementos e não têm potencial para aumentar a ecoeficiência do negócio. Haja vista, contribuem para o desenvolvimento sustentável, de forma geral, como adotar a Agenda 21 ou seguir os Princípios do Equador e, de 
forma específica, como fornecer educação ambiental à comunidade, participar de proje- tos voltados para algum processo de reciclagem, recuperar e preservar áreas.

\section{A PESQUISA EMPÍRICA}

A ação ecológica empresarial é a variável analisada por este artigo. A pesquisa empírica pode servir para o pesquisador observar o comportamento da variável na realidade em um ou diversos contextos. Para isso, três elementos são contemplados: os materiais abordados, a população observada e a análise dos resultados. Os materiais são escolhidos para se chegar à população e efetuar a análise dos resultados.

Este trabalho encontra divulgação de ações ecológicas empresariais em três tipos de materiais: nos projetos premiados como "práticas de destaque área meio ambiente" pelo Guia Exame da Boa Cidadania Corporativa (GEBCC) produzido pela Revista Exame; nos projetos divulgados como "cases premiados" pelo Benchmarking Ambiental (BA) elaborado pela empresa Mais Projetos Corporativos (MPC) (2006) e nos Relatórios Anuais de 2005 das empresas listadas no ISE 2005 da BOVESPA.

Tanto no GEBCC quanto no BA, as empresas enviam seus projetos para aprovação de uma comissão técnica. Os aprovados são premiados e divulgados na mídia. A escolha das empresas foi guiada por essas premiações. Os Relatórios Anuais são obrigações anuais para empresas Sociedade Anônima Abertas cujas ações são negociadas na BOVESPA. Espera-se que as listadas no ISE divulguem informações sobre a manutenção de atividades ecológicas empresariais. Por isso, as empresas S.A. abertas escolhidas fazem parte do ISE.

A seguir, são descritos os três tipos de materiais abordados por este trabalho para efetuar a análise de conteúdo: GEBCC, BA e Relatório Anual 2005 ISE 2005.

- Guia Exame de Boa Cidadania Corporativa (GEBCC)
Referência: GEBCC (2002), GEBCC (2003), GEBCC (2004) e GEBCC (2005)

O GEBCC é uma publicação anual da Revista Exame e visa disseminar e estimular melhores práticas de responsabilidade corporativa. Foi criado em 2000 em parceria com o Instituto Ethos de Empresas e Responsabilidade Social para premiar projetos envolvidos com a sustentabilidade empresarial. A Revista Exame já publicou seis edições do GEBCC: 2000, 2001, 2002, 2003, 2004 e 2005.

Dentro de seu conteúdo, há uma parte destinada à publicação das "práticas de destaque" nas áreas relacionadas aos sete temas dos indicadores Ethos (2006): valores e transparência; funcionários; fornecedores; consumidores/clientes; comunidade; governo/ sociedade e meio ambiente.

Os projetos analisados por este trabalho são os premiados como "práticas de destaque área meio ambiente" publicados nas edições de 2002, 2003, 2004 e 2005: GEBCC (2002), GEBCC (2003), GEBCC (2004) e GEBCC (2005).

- Benchmarking Ambiental (BA) Referência: BA (2003), BA (2004) e BA (2005)

Há, também, exemplos de ações ecológicas empresariais nos projetos publicados no site Mais Projetos Corporativos (MPC) (2006) (http://www.maisprojetos.com.br) por meio da divulgação do BA - Benchmarking Ambiental para premiar e divulgar práticas empresariais relacionadas com a proteção do meio ambiente. O MPC já publicou três edições do BA: 2003, 2004, 2005 e 2006. Este trabalho aborda todos os projetos premiados pelo BA das edições de 2003, 2004 e 2005: BA (2003), BA (2004) e BA (2005). 
Além desses dois tipos de material, GEBCC e BA, este artigo aborda um terceiro e último conjunto de dados: os Relatórios Anuais 2005 das S.A.s com ações listadas no ISE 2005 da BOVESPA.

\section{- Relatórios Anuais das Empresas Lis- tadas no ISE 2005}

Conforme a Bolsa de Valores de São Paulo (BOVESPA) (2006) e Monzoni, Biderman e Brito (2006), o Índice de Sustentabilidade (ISE) tem como objetivo promover práticas empresariais que integram desempenho econômico, social e ecológico em seus negócios e demonstrar os retornos de uma carteira composta por ações de empresas consideradas sustentáveis.

Para o desenvolvimento do ISE foi formado um Conselho Deliberativo presidido pela BOVESPA. As demais organizações que participam do desenvolvimento são: Associação Brasileira das Entidades Fechadas de Previdência Complementar (ABRAPP), Associação Nacional dos Bancos de Investimentos (ANBID), Associação dos Analistas e Profissionais de Investimento do Mercado de Capitais (APIMEC), Instituto Brasileiro de Governança Corporativa (IBGC), International Finance Corporation (IFC), Instituto ETHOS e Ministério do Meio Ambiente.

Para selecionar as empresas que compõem o ISE o CES-FGV (Centro de Estudos de Sustentabilidade da Fundação Getúlio Vargas) desenvolveu um questionário para medir o desempenho das companhias emissoras das 150 ações mais negociadas na BOVESPA. O questionário procura abordar o conceito Triple Bottom Line (TBL), desenvolvido pela consultoria inglesa SustainAbility, que envolve a avaliação de elementos ambientais, sociais e econômico-financeiros, assim como a posição da empresa perante acordos globais, publicações sociais e governança corporativa.

A primeira carteira, ISE 2005, entrou em vigor no dia 1 de dezembro de 2005 com va- lidade até 1 de dezembro de 2006. Logo, em 1 de dezembro de 2006 foi formada a carteira ISE 2006 com validade até 1 de dezembro de 2007.

A ISE 2005 era composta por 34 ações de 28 empresas: América Latina Logística, Aracruz Celulose e Papel, Banco do Brasil, Arcelor, Bradesco, Braskem, CCR Rodovias, Celesc, Cemig, Cesp, Copel, Copesul, CPFL Energia, DASA Diagnóstico da América, Eletrobrás, Eletropaulo, Embraer, Gol Linhas Aérea Inteligentes, Iochpe-Maxion, Itaú Holding, Itausa, Natura, Perdigão, Suzano Bahia Sul Papel e Celulose, Tracbel Energia, Unibanco, Votarantim Celulose e Papel e WEG.

O Relatório Anual pode ser utilizado pelas empresas para fornecer informações aos diversos públicos da sociedade sobre a evolução e atuação de seus negócios em determinado período. Documento oficial corporativo, o Relatório Anual apresenta as informações do Relatório da Administração, juntamente com as Demonstrações Contábeis, acompanhadas dos pareceres dos Auditores Independentes e do Conselho Fiscal. Podem conter gráficos, fotografias e tabelas.

Conforme Iudícibus, Martins e Gelbcke (2003), a Comissão de Valores Mobiliários (CVM) faz recomendações sobre o conteúdo do Relatório de Administração. No Parecer de Orientação n ${ }^{\circ}$. 15/87 citam-se itens que nele devem constar. Um desses itens é a divulgação de informação sobre a proteção do meio ambiente por parte da empresa, ou seja, essa parte do Relatório Anual pode conter exemplos de ações ecológicas empresariais.

Acredita-se que, nos Relatórios Anuais das empresas listada no Índice de Sustentabilidade Empresarial (ISE) da Bolsa de Valores da São Paulo (BOVESPA), podem ser identificadas ações ecológicas empresariais por serem consideradas pelo CES-FGV como empresas sustentáveis. Empresas sustentáveis, geralmente, programam e divulgam atividades ambientais. 
A identificação da ação ecológica é possível por meio da leitura analítica do Relatório Anual 2005 de cada empresa observada, principalmente dos trechos reservados para assuntos relacionados com a proteção do meio ambiente.

O processo de coleta de dados consiste em identificar nesses três tipos de materiais - GEBCC, BA e Relatórios Anuais 2005 ISE 2005 - exemplos de ações ecológicas empresariais e por meio da análise de suas finalidades enquadrá-las nas categorias propostas. Dessa forma, este trabalho aborda a população a fim de verificar a variável finalidade da ação ecológica empresarial em diversos contextos empresariais e responder à pergunta de pesquisa sobre como categorizar as ações ecológicas empresariais.

Dentre todas as premiações citadas nas três bases retrodiscriminadas: GEBCC, BA e Relatório Anual 2005 ISE 2005, identificaram-se e analisaram-se 608 ações ecológicas empresariais. Dessas, 458 são encontradas nos projetos premiados como "práticas de destaque na área meio ambiente" pelos GEBCC; 32 estão nos “cases premiados" pelos BA e 118 localizam-se nos Relatórios Anuais das empresas pertencentes ao ISE 2005.

As 608 ações ecológicas identificadas são mantidas por 181 empresas. Dessas, 16 são companhias S.A. abertas com ações listadas no ISE 2005; 55 também são companhias S.A. abertas, mas suas ações não estão listadas no ISE 2005 e 110 pertencem ao conjunto das companhias S.A. fechadas ou Ltda. Note-se que a maioria das ações ecológicas foi encontrada em projetos de companhias S.A. fechadas e Ltda., 60,77\% (110/181). Esperava-se que os projetos das companhias S.A abertas tivessem maior repercussão.

Os setores que apresentaram 10 empresas ou mais foram os: automotivo, químico e petroquímico, serviços diversos, serviços públicos e siderurgia e metalurgia. Resultado compatível com as expectativas. Todos são setores poluentes e estratégicos para a economia de um país, por isso necessitam manter ações ecológicas e compatibilizar desempenho econômico com o ecológico em busca da sustentabilidade empresarial.

O setor com maior número de ações ecológicas identificadas é o de serviços públicos, compreendido por empresas de energia e água. Esse setor, em conjunto com os setores químico e petroquímico, papel e celulose, siderurgia e metalurgia e bancos e serviços financeiros, detém mais de 50,0\% das ações ecológicas empresarias identificadas.

No entanto, não significa dizer que esses setores mantêm mais atividades ambientais que os demais, pois, como os dados não representam o total de ações ecológicas mantidas por todas as empresas, não podem expressar qual empresa ou setor mais programam ações ecológicas. O Resultado indica que, em quase todos os setores da economia brasileira, há evidências de manutenção de ações ecológicas empresariais.

\section{ANÁLISE DOS RESULTADOS}

Este artigo identifica exemplos de atividades ambientais nos três tipos de materiais e as enquadra em duas categorias: ação ecológica que atua sobre os resíduos emitidos pela própria empresa durante o processamento de seus produtos e serviços ou em ação ecológica que atua sobre elementos não relacionados com os resíduos emitidos pela própria empresa durante o processamento de seus produtos e serviços.
Conforme os resultados, as empresas mantêm atividades ambientais para atuar tanto sobre os próprios resíduos quanto sobre outros elementos. Há ocorrência de ações ecológicas empresarias com e sem potencial para aumentar a ecoeficiência do negócio. Do total de 608, 158 (25,99\%) atuam sobre os resíduos emitidos pela própria empresa durante o processamento de seus serviços e 
produtos e $450(74,01 \%)$ agem sobre outros elementos.

As 158 ações ecológicas empresariais que atuam sobre os resíduos do próprio negócio apresentam finalidades como: reduzir o uso de insumo, substituir os insumos não renováveis por renováveis, recicláveis ou retirados de forma ecológica (direção I); transformar resíduos em insumos (direção II); transformar resíduos em produtos (direção III); adequar-se a contratos, neutralizar o efeito tóxico do resíduo, promover a coleta seletiva de lixo e reduzir a emissão de resíduos (direção IV). Portanto, conforme os resultados as empresas agem sobre seus próprios resíduos em quatro direções:

- Direção I: a empresa pode agir logo no início do processamento de seus produtos e serviços para reduzir o uso dos insumos e substituir insumos não-renováveis por renováveis ou retirados de forma ecológica. Mesmo não tendo contato com resíduos pode diminuir sua geração, pois ao melhorar o uso e a qualidade dos insumos pode, consequentemente, reduzir a emissão de detritos.

Ações ecológicas empresariais com finalidades nessa direção podem ser encontradas nos Relatórios Anuais 2005 da Natura, ALL, Tracbel Energia, Perdigão, Suzano Bahia Sul Papel e Celulose, Votorantim Papel e Celulose, Arcelor, Iochpe-Maxion. Nessa mesma direção, encontra-se os projetos da Volkswagen, do Banco ABN Amro Real e da Natura premiados pelo GEBCC (2005) e da V \& M Florestal premiado pelo BA (2003).

No projeto da Natura, premiado pelo GEBCC (2004), identifica-se exemplo de ação ecológica empresarial com a finalidade de estimular a compra de insumos retirados de forma ecológica. A finalidade da ação ecológica identificada no projeto premiado pelo GEBCC (2004) da Daimler Chrysler é utilizar materiais de fontes renováveis, isto é, substituir insumos não-renováveis por renováveis.

No projeto da Lafarge premiado pelo GEBCC (2004), a empresa utiliza resíduos industriais como insumos no processo de produção de cimento. Essa prática conforme Barros (2006) está se transformando em uma tendência entre as indústrias de cimentos do Brasil. Segundo Barros (2006), além da Lafarge, as empresas como Votorantim Cimentos e Holcin também já queimam lixo industrial no lugar do coque do petróleo em seus fornos e com isso conseguem reduzir custos.

Ações ecológicas com a finalidade de reduzir o uso de insumos podem ser encontradas no projeto da Intermédica Sistemas de Saúde premiado pelo GEBCC (2004), no projeto da Fiat e da Aracruz premiados pelo GEBCC (2005), no projeto da Ambev premiado pelo BA (2003), no da AstraZeneca premiado pelo BA (2004), nos Relatórios Anuais da Braskem etc.

- Direção II: a empresa pode reduzir o uso de insumos por meio da transformação de resíduos em matéria-prima e permitir, assim, seu reaproveitamento internamente no processo produtivo. Nessa direção, o resíduo já foi liberado e por isso a empresa pode trabalhar com ele a fim de permitir sua entrada novamente no sistema empresa.

Ações ecológicas com essa finalidade podem ser localizadas no Relatório Anual 2005 da Perdigão. Essa utiliza resíduos para geração de energia para suprir suas próprias necessidades, ou seja, transforma resíduo (gasoso) em insumo (energia). As empresas podem, também, transformar as águas residuais no insumo água por meio da manutenção de sistemas de reuso da água.

Programas desse tipo são encontrados nos projetos da CST premiado pelo BA (2005), nos Relatórios Anuais 2005 da Arcelor, DASA, Suzano Bahia Sul Papel e Celulose, Votorantim Papel e Celulose, CPFL, da Tracbel Energia, ALL e da Natura. No site da AGCO, também, há informação sobre a ocorrência de recirculação da água em seus processos.

Identifica-se, assim, um padrão em ações com a finalidade de transformar resíduo em insumo. Independente do setor ou formato a maioria delas visa ao reuso da água contida 
no efluente. Muitas empresas podem investir em tecnologias inovadoras que possibilitem uma taxa de $100 \%$ de recirculação de água.

- Direção III: ações ecológicas que visam a transformar resíduos em produtos. As empresas investem nessas atividades com a finalidade de atuar sobre seu resíduo para criar valor e fazer do lixo um produto com valor de mercado. Nessa direção, o resíduo já foi liberado e a empresa pode trabalhar para permitir sua saída do sistema empresa como produto.

Esse tipo de ação pode ser encontrado: nos projetos da Sortex Plásticos e Metais, da Cimento Itambé, da Sobloco e da GKN premiados pelo GEBCC (2002); no projeto da Aché e da Daimler Chysler premiados pelo GEBCC (2003); nos projetos da Henkel, da Albras, Zema, Elektro, AIX Sistemas, IBM e Multibrás premiados pelo GEBCC (2005); no projeto da Sabesp premiado pelo BA (2004) e nos Relatórios Anuais 2005 de algumas companhias S.A. abertas com ações listadas no ISE 2005.

- Direção IV: o quarto conjunto de ações ecológicas, ou quarta direção, tem como finalidade a redução na emissão de resíduos, a neutralização do efeito tóxico de seus detritos, responsabilidade contratual e coleta seletiva de lixo. Nessa direção, o resíduo já foi liberado e não tem condições de ser reaproveitado como insumos ou vendido como produto. A empresa gerencia os detritos para que não contaminem os ecossistemas.

Berry e Rondinelli (1998) explicam que os gastos em proteção ambiental, num primeiro momento, são incorridos em ações ecológicas de conformidade. A primeira atividade ambiental programada pode ser para adequar o processo produtivo à legislação ambiental. Com o passar dos tempos, as empresas veem oportunidades com a sustentabilidade ecológica e, então, passam a investir em projetos que agregam valor aos resíduos (Direção II e III).

Ações ecológicas que visam a reduzir a emissão de resíduos são encontradas nos Re- latórios Anuais 2005 da Braskem, Arcelor, Perdigão e Natura. Há exemplos de ações ecológicas que visam à certificação ISO 14.001, voltados aos Sistemas de Gestão Ambiental, nos projeto da COSIPA (BA 2004), do SENAI (BA 2004), do Centro de Cuidados e Desenvolvimento Infantil Materna Ltda (BA 2005) nos Relatórios Anuais 2005 da ALL, IochpeMaxion, Arcelor, Embraer, Votorantim, Cemig, CPFL, Eletropaulo, Tracbel Energia e Natura.

Note-se que, muitas vezes, para transformar resíduos em insumos ou em produtos a empresa necessita fazer coleta seletiva de lixo. Mas pode fazer coleta seletiva de lixo e não aproveitar o resíduo como insumos e não vendê-lo como produto. Coleta seletiva de lixo dessa forma pode ser encontrada no projeto das empresas Hotelaria Accor (GEBCC 2002), Kodak (GEBCC 2003), Dixie Toga (GEBCC 2004), Vivo (GEBCC 2005), Unimed (BA 2003), Newpower Sistemas de Energia Ltda (BA 2005), Unibanco (Relatório Anual 2005) etc (GEBCC 2005 e em outros Relatórios Anuais 2005 ISE 2005).

Reduzir a emissão de resíduos pode ser por meio da reciclagem dos resíduos aproveitando-os como insumos ou pela sua venda. Mas, também, pode ser feita via instalação de filtros ou algo semelhante. Somente em situação como essas que a finalidade da ação ecológica empresarial é reduzir a emissão de resíduo. Ação ecológica empresarial com essa finalidade somente foi encontrada no material Relatório Anual 2005 ISE 205. Empresas como Braskem, Arcelor, Perdigão e Natura divulgam manter atividades ambientais para esse fim.

Ações programadas para neutralizar o efeito tóxico dos resíduos emitidos pela própria companhia são localizadas nos projetos da Alcoa (GEBCC 2002), Aracruz (GEBCC 2004), Multibrás (GEBCC 2005), Portobello S.A. (BA 2005) etc. Nos Relatórios Anuais de empresas do ISE 2005, também, há exemplos de ações com essa finalidade. 
As quatro finalidades que aparecem com maior frequência são: transformar resíduos em produtos $(20,25 \%)$; neutralizar o efeito tóxico dos detritos (17,1\%); responsabilidade contratual $(18,82 \%)$ e transformar resíduos em insumos (14,56\%). Em relação às direções, 47,47\% das ações ecológicas empresariais estão na IV; $20,25 \%$ na III; $17,72 \%$ na I e $14,55 \%$ na II.

Ações que atuam fora dessas direções podem ser enquadradas na outra categoria. Há 450 ações ecológicas empresariais que atuam sobre elementos não relacionados com os próprios emitidos pela própria empresa durante o processamento de seus produtos e serviços. Conforme os resultados $41,2 \%$ dessas 450 ações são projetos de educação ambiental, 40,0\% são para preservar áreas e recuperar locais poluídos, 14,67\% são programas de reciclagem e 3,33\% são atividades voltadas para o desenvolvimento sustentável de forma geral.

O compromisso com a Agenda 21 da empresa Caterpillar (GEBCC 2002), Embratel (GEBCC 2005 e BA 2003), Eletrobrás (Relatório Anual 2005 ISE 2005) e da Natura (Relatório Anual 2005 ISE 2005) e adoção dos Princípios do Equador pelo Banco Real (GEBCC 2002), Itaú (GEBCC 2005), Banco do Brasil (Relatório Anual 2005 ISE 2005) e Unibanco (Relatório Anual 2005 ISE 2005) exemplificam ações ecológicas empresariais voltadas para promover o desenvolvimento sustentável de forma geral.

Os projetos da MBR, 3M, Bayer, WEG, Carterpillar, Ambev, Suzano Bahia Sul Papel e Celulose premiados pelo GEBCC (2002), CPFL, Sabesp, Souza Cruz e Philips pelo GEBCC (2003), Aracruz, Suzano Bahia Sul Papel e Celulose pelo GEBCC (2004), Arcelor pelo GEBCC (2005), entre outros, contêm exemplos de ações ecológicas que visam ao funcionamento de programas de educação ambiental à comunidade.

A Alcoa (GEBCC 2003), Vega (GEBCC 2002), Grupo Pão de Açúcar (GEBCC 2003),
Copesul (GEBCC 2003), Ripasa (GEBCC 2003), Petroquímica União (GEBCC 2003), Cocomar (GEBCC 2003), Cenibra (GEBCC 2004), Itaúsa (Relatório Anual 2005 ISE 2005), entre outras, apresentam ações ecológicas voltadas para projetos de reciclagem.

As companhias Dupont e Petrobras (GEBCC 2002), CPFL (GEBCC 2003), Sabesp (GEBCC 2003), Aracruz e Suzano Bahia Sul Papel e Celulose (GEBCC 2004), Citibank (GEBCC 2004), Emae (GEBCC 2005), Alpha Ville Urbanismo (GEBCC 2005), Embratel (GEBCC 2005), Acesita (GEBCC 2005), entre outras, investem em programas de recuperação e preservação.

De forma geral, esperava-se que as empresas mantivessem um número maior de ações ecológicas com potencial para aumentar a ecoeficiência do negócio, porém os resultados desta pesquisa demonstram outra situação. Ressalte-se, também, que sobre a perspectiva contábil faltaram informações para analisar a consequência econômico-financeira dos gastos incorridos em ações ecológicas empresariais. Estudos futuros poderiam ser direcionados para calcular os valores e resultados envolvidos com os ativos voltados à proteção do meio ambiente.

Toda finalidade identificada se enquadrou na proposição. Toda ação ecológica empresarial pode atuar sobre elementos não relacionados com os resíduos emitidos pela própria empresa durante o processamento de seus produtos e serviços por meio da manutenção de programas voltados ao desenvolvimento sustentável de forma geral ou específica como educação ambiental, reciclagem, preservação e recuperação. Quando agem sobre os resíduos emitidos pela própria empresa durante o processamento de seus serviços e produtos, a finalidade pode se enquadrar nas quatro direções da proposição.

A proposição mostra-se, então, adequada para gerenciar os gastos e resultados incorridos nas atividades ambientais com potencial para influenciar a ecoeficiência do negócio. $\mathrm{O}$ 
objetivo da Contabilidade, segundo Iudícibus e Marion (2000), é fornecer informações úteis para tomadas de decisões. Por isso, o sistema contábil pode ser estruturado para garantir o fornecimento de informações relevantes sobre diversos eventos. A Contabilidade da Gestão Ambiental pode representar uma dessas estruturas.

Este artigo compreende a Contabilidade da Gestão Ambiental como a provedora de in- formações sobre a consequência econômicofinanceiro-ambiental-operacional de manter ações ecológicas empresariais. Para gerenciar a ecoeficiência do negócio, podem-se criar indicadores para visualizar os fluxos físico e monetário envolvidos com os inputs, outputs e outputs não-produto do sistema empresa e o efeito das ações ecológicas empresariais sobre esses fluxos.

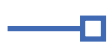

\section{CONSIDERAÇÕES FINAIS}

Sustentabilidade Empresarial pode ser alcançada por meio da manutenção de ações ecológicas que convergem para a ecoeficiência. Outras atividades ambientais podem contribuir para a proteção do meio ambiente, mas não reduzem o impacto negativo do próprio negócio. Atenta a isso, a Contabilidade da Gestão Ambiental pode categorizar as ações ecológicas empresariais e possibilitar o fornecimento de informações sobre os eventos relacionados com a ecoeficiência do negócio.

Este artigo enquadra as ações ecológicas empresariais em duas categorias: $\boldsymbol{\nabla}$ ação ecológica que atua sobre elementos relacionados com os resíduos emitidos pela própria empresa durante o processamento de seus produtos e serviços; - ação ecológica que atua sobre elementos não relacionados com os resíduos emitidos pela própria empresa durante o processamento de seus produtos e serviços.

De acordo com os resultados, a Contabilidade da Gestão Ambiental pode criar indicadores físicos e monetários para ações que atuam em elementos não relacionados com os próprios resíduos. Calcular quantas pessoas participaram dos programas de educação ambiental, tamanho da área recuperada e preservada, quantidade de material externo reciclado, número de programas ambientais patrocinados pelo negócio e os gastos incorridos nessa categoria de ações ecológicas empresariais são exemplos dessas possibilidades.
Também podem ser criados indicadores físicos e monetários para as ações ecológicas que agem sobre os resíduos emitidos pelas próprias operações do negócio. Além de visualizar o fluxo físico e monetário envolvidos com os inputs e outputs do sistema empresa, indicam o efeito das ações ecológicas nesses fluxos. Exemplo: indicadores físicos sobre a redução do uso de insumos, taxa de recirculação da água, quantificação de resíduos sólidos reutilizados ou vendidos, quantificação das certificações obtidas por certo período etc; e indicadores monetários para calcular o valor investido e confrontar com as reduções de custos, incremento de receitas e conquista de novos mercados.

Os conceitos da UN (2001, p. 42), do Sistema Empresa Ecoeficiente de Vellani e Ribeiro (2006), do Valle (2000), da Contabilidade da Gestão Ambiental de Burritt e Saka (2005) as práticas empresariais, a proposição deste estudo e a pesquisa empírica resultam num Sistema de Gestão da Ecoeficiência Empresarial. A Figura $2 \bigcirc$ aponta um caminho para a Contabilidade da Gestão Ambiental evoluir.

A gestão física e monetária da ecoeficiência empresarial visualiza a empresa como um sistema. Há entradas de insumos (inputs) e saídas de produtos, serviços (outputs) e resíduos (outputs não-produto). Medir esse desperdício fisicamente possibilita calcular quanto das entradas não se transformou em produtos $\mathrm{e}$ serviços. Monetariamente, o gestor pode me- 


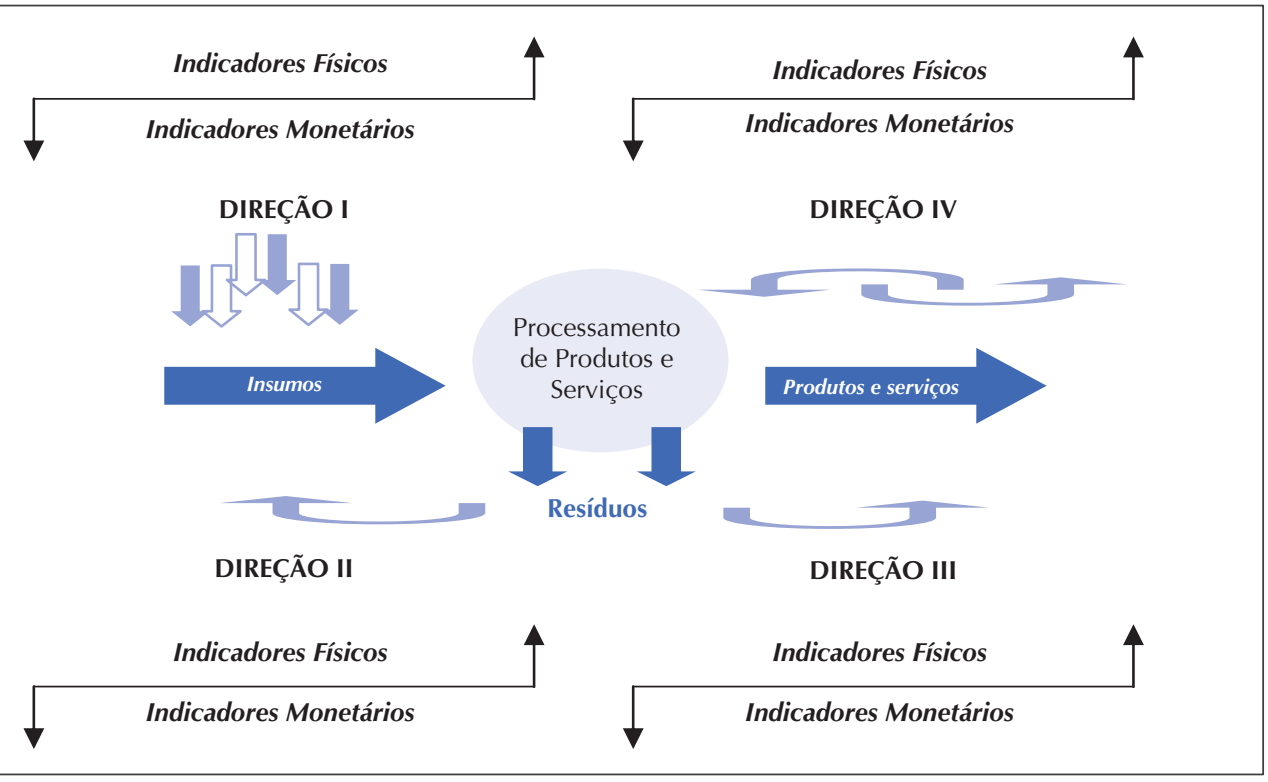

Figura 2 Sistema de Gestão Física e Monetária da Ecoeficiência Empresarial

dir quanto do capital aplicado em insumos é desperdiçado em forma de resíduos.

A Figura 2 visualiza o fluxo monetário e físico de entradas e saídas no sistema empresa. As ações ecológicas empresariais internas (AEE internas) têm a capacidade de alterar esses fluxos. Substituir insumos não-renováveis por renováveis, recicláveis ou retirados de forma ecológica; reduzir o consumo de insumos; transformar resíduos em insumos; transformar resíduos em produtos; reduzir a emissão de resíduos, neutralizar o efeito tóxico dos resíduos, coleta seletiva de lixo ou responsabilidade contratual são exemplos de finalidades de ações ecológicas capazes de alterar o fluxo físico e monetário das entradas e saídas do sistema empresa.

Para todo conjunto de atividade ambiental dentro da empresa também podem ser criados indicadores físicos e monetários para avaliar o desempenho ecológico e econômico da ação ecológica empresarial. Ademais, podem indicar quais atividades ambientais conseguem integrar desempenho econômico com ecológico. Demonstram se a companhia mantém ações ecológicas para resgatar a harmonia entre os elementos dos ecossistemas de forma direta ou indireta. Uma empresa que atua de forma direta para resgatar a harmonia entre os elementos dos ecossistemas, certamente, está mais próxima da ecoeficiência e da sustentabilidade que daquela que mantém somente atividades ambientais que não atuam sobre seus próprios resíduos.

Exemplo: determinada empresa A investe em ações que visam à recirculação da água, pois trata de seu único resíduo: água tóxica. $\mathrm{E}$ consegue com isso redução de custos. Outra, a empresa $\mathrm{B}$ investe em programas ambientais para fornecer educação ambiental à comunidade e mantem uma estação de tratamento de efluente para tratar de seu único resíduo também água tóxica, mas sem recirculação da água e sem obter redução de custos. A terceira firma, C, possui o mesmo processo de recirculação da água da empresa A e o mesmo programa de educação ambiental da $B$.

Considera-se que as três empresas têm o mesmo faturamento e o único resíduo liberado é o mesmo para todas: água tóxica. A questão é: qual empresa é mais ecoeficiente? Qual empresa é mais sustentável?

Certamente a empresa A e C é mais ecoeficiente que $\mathrm{B}$, pois consegue gerenciar seus 
resíduos de tal forma que consegue utilizar menos o recurso natural água e obter benefícios econômicos com isso. Apesar de a empresa B educar a comunidade sobre ecologia, os ecossistemas da Terra continuarão a ser contaminados pela água tóxica liberada durante o processamento de seus serviços e produtos.

Fornecer educação ambiental à comunidade pode contribuir para o aumento de desempenho social uma vez que dissemina o conhecimento sobre ecologia entre a sociedade. Logo, pode melhorar sua sustentabilidade. Esse tipo de ação ecológica age de forma indireta para resgatar a harmonia entre os elementos que formam os ecossistemas.

Em termos de sustentabilidade, as empresas A e B podem estar no mesmo nível visto que ambas investem em alguma dimensão da sustentabilidade empresarial, porém, como o programa de reciclagem da empresa A possibilita redução de custos e integração entre desempenho ecológico e econômico, ela é mais ecoeficiente que sua concorrente B. Logo, é mais sustentável por conseguir integrar desempenho ecológico com econômico.

A empresa mais sustentável das três é a empresa $\mathrm{C}$, pois consegue integrar desempenho ecológico e econômico com o programa de recirculação de água e obter desempenho social com seu programa de educação ambiental, ou seja, consegue integrar desempenho econômico, social e ecológico. Em termos de ecoeficiência, as empresas A e C estão no mesmo nível, pois utilizam a mesma tecnologia para transformar o resíduo água tóxica em insumo e obter com isso, redução de custos.

O caminho para a sustentabilidade consiste na manutenção de ações que consigam trazer ao negócio desempenho econômico, social e ecológico. Além disso, para prover os gestores de informações úteis para tomadas de decisões, a Contabilidade pode evoluir e se estruturar para atender às novas necessidades de seus usuários. Há duas categorias para as ações ecológicas empresariais.

$\mathrm{Na}$ categorização proposta, as ações ecológicas que podem aumentar a ecoeficiência do negócio ficam separadas dos programas voltados ao desenvolvimento sustentável da sociedade, mas externos ao negócio da empresa. Isso organiza os gastos e resultados incorridos nas ações ecológicas empresariais. Gera informação sobre o caminho para a empresa integrar desempenho ecológico e econômico. Contribui para o gestão da ecoeficiência do negócio.

Coulson e Thompson (2006) refletem sobre inserir a sustentabilidade nas grades dos cursos de Contabilidade. Quiçá essa nova estrutura da ciência contábil possa ser incorporada. Haja vista, sugerem-se novos estudos para verificar a eficácia desse sistema. Há dois possíveis caminhos: identificar outras ações ecológicas em outras empresas ou aplicar a proposta deste artigo em alguma companhia.

Contudo, o objetivo deste trabalho foi alcançado. Identifica-se uma forma de organização contábil capaz de fornecer informações sobre os fluxos monetário e físico envolvidos com inputs e outputs do sistema empresa. Também é capaz de disponibilizar informação sobre o efeito das ações ecológicas nesses fluxos. Esse tipo de informação pode ser divulgado pelo subsistema da ciência contábil: Contabilidade da Gestão Ambiental.

\section{Referências}

ALMEIDA, F. O Bom negócio da sustentabilidade. Rio de Janeiro: Nova Fronteira, 2002.

Al-TUWAIJRI, S.; CHRISTENSEN, T. E.; HUGHES II, K. E. The relations among environmental disclosure, environmental performance and economic performance: a simultaneous equations approach. Social Science Research Network, Jul 2003.

BA, Benchmarking Ambiental. Cases premiados no $1^{\circ}$ Benchmarking Ambiental. Brasil: Mais projetos corporativos, 2003. Disponível em: <http://www. 
maisprojetos.com.br/bench/resumo_2003.htm>. Acesso em: 19 jun. 2006.

. Cases premiados no $2^{\circ}$ Benchmarking Ambiental.

Brasil: Mais projetos corporativos, 2004. Disponível em: $<$ http://www.maisprojetos.com.br/bench/resumo_2004. htm>. Acesso em: 19 jun. 2006.

Cases premiados no $3^{\circ}$ Benchmarking Ambiental.

Brasil: Mais projetos corporativos, 2005. Disponível em: $<$ http://www.maisprojetos.com.br/bench/resumo_2005. htm>. Acesso em: 19 jun. 2006.

BOVESPA, Bolsa de Valores de São Paulo. Índice de Sustentabilidade Empresarial. São Paulo, BOVESPA, 2006. Disponível em: <http://www.bovespa.com.br/Pdf/ Indices/ISE.pdf>. Acesso em: 23 maio 2006.

BARROS, B. Cimenteira troca coque por "lixo" nos fornos e reduz custos. Jornal Valor Econômico, São Paulo, $4 \mathrm{dez}$. 2006. Empresas, p. B7.

BELKAOUI, A. The impact of the disclosure of the environmental effects of organization behavior on the Market. Financial Management, p. 26-31, 1976.

BRAMER, S.; BROOKS, C.; PAVELIN, S. Corporate social performance and stocks returns: UK evidence from disaggregates measures. Financial Management, v. 35, n. 3, p. 97, 2006.

BURRITT, R. L. Environmental reporting in Australia: current practices and issues for the future. Business Strategy Environmental, v. 11, n. 6, Nov./Dez. 2002. . Environmental management accounting: roadblocks on the way to the green an pleasant land. Business Strategy Environmental, v. 13, n. 1, Jan./Feb. 2004.

; SAKA, B. C. Environmental management accounting applications and eco-efficiency: case studies from Japan. Journal of Cleaner Production, ABI/INFORM Global, v. 14, n. 14, p. 1262-1275, 2005.

BERRY, M. A.; RONDINELLI, D. A. Proactive corporate environment management: a new industrial revolution.

The Academy of Management Executive, Briarcliff Manor, v. 12, n. 2, p. 38, may 1998.

COLLIS, J.; HUSSEY, R. Pesquisa em administração: um guia prático para alunos de graduação e pós-graduação.

Tradução Lucia Simonini. 2. ed. Porto Alegre: Bookman, 2005.

\section{COPESUL, COMPANHIA PETROQUÍMICA DO}

SUL. Indicadores de controle ambiental: resíduos sólidos, segurança, saúde e meio ambiente, Relatório de Desempenho 2004. Relatório Anual 2004 COPESUL. Brasil: COPESUL, 2004.

COULSON, A.; THOMSON, I. Accounting and sustainability, encouraging a dialogical approach; intregratig learning activities, delivery mechanisms and assessment strategies. Accounting Education: an internacional journal, v. 15, n. 3, p. 261-273, Sept. 2006. FERREIRA, C. Environmental accounting: the Portuguese case. Management of Enviornmental Quality, v. 15, n. 6 , p. 561, 2004.

GEBCC, GUIA EXAME DE BOA CIDADANIA

CORPORATIVA. Práticas de destaque: meio ambiente. Revista Exame, Brasil, 2002. 3 v., dezembro, 2002. Práticas de destaque: meio ambiente. Revista

Exame, Brasil, 2003. 4 v., dezembro, 2003.
Práticas de destaque: meio ambiente. Revista

Exame, Brasil, 2004. 5 v., dezembro, 2004.

Práticas de destaque: meio ambiente. Revista

Exame, Brasil, 2005. 6 v., dezembro, 2005.

GIBSON, K. C.; E MARTIN, B. A. Demonstrating value through the use of environmental management accounting. Environmental Quality Management, v. 13, n. 3, p. 45, Spring 2004.

GVCES, CENTRO DE ESTUDOS EM SUSTENTABILIDADE DA FUNDAÇÃO GETÚLIO

VARGAS. Institucional, apresentação. São Paulo: Fundação Getúlio Vargas, 2006. Disponível em: <http:// ces.fgvsp.br/?fuseaction $=$ content $\&$ IDassunto $=43 \&$ IDidio $\mathrm{ma}=1>$. Acesso em: 09 mar. 2006.

HELMINEN, R. Developing tangible measures for eco-efficiency: the case of finnish and Swedish pulp and paper industry. Business strategy and the environment, ABI/INFORM Global, v. 9, n. 3, p. 196, may-june 2000. $\mathrm{HOH}, \mathrm{H}$;; SCHOER, K.; SEIBEL, S. Eco-efficiency indicators in German Environmental economic accounting. Statistical Journal of the UN Economic Commission for Europe, v. 19 n. 1/2, p. 41, 2002. IUDÍCIBUS, S., MARION, J. C. Curso de contabilidade para não Contadores. 3. ed. São Paulo: Atlas, 2000 ; MARTINS, E.; GELBCKE, E. R. Manual de contabilidade das sociedades por ações: aplicável às demais sociedades. 6. ed. São Paulo: Atlas, FIPECAFI, 2003.

LODHIA, S. K. Environmental accounting in Fuji: an extende case study of the Fuji Sugar Corporation. Journal of Pacific Studies - Banking, Finance and Accounting Special Issue, v. 23, n. 2, p. 283-309, Nov. 1999.

MARSHALL, R. S.; BROWN, D. Corporate environmental reporting: what's in a metric? Business Strategy and the Environment, v. 12, n. 2, Mar./Apr. 2003. MARTIN, B. Environmental accounting. Financial Management, p. 36-37, Apr. 2007.

MARTINS, G. A. O estudo de caso: uma estratégia de pesquisa. São Paulo: Atlas, 2006.

MAY, P. H.; LUSTOSA, M. C.; VINHA, V. (Orgs.).

Economia do meio ambiente. 2 ed. Rio de Janeiro:

Elsevier, 2003.

MONZONI, M.; BIDEMAN, R.; BRITO, R. Finanças sustentáveis e o caso do Índice de Sustentabilidade empresarial da BOVESPA. In: SIMPÓSIO DE ADMINISTRAÇÃO DA PRODUÇÃO, LOGÍSTICA E OPERAÇÕES INTERNACIONAIS, 9., 2006, São Paulo. Anais... São Paulo: Fundação Getúlio Vargas-SP, 2006. MPC, Mais Projetos Corporativos. Benchmarking Ambiental. Brasil: MPC, 2006. Disponível em: <http:// www.maisprojetos.com.br/bench/>. Acesso em: 12 jan. 2006.

ONU, Organização das Nações Unidas. Contabilidade da gestão ambiental: procedimentos e princípios. Divisão para o Desenvolvimento Sustentável das Nações Unidas Nações Unidas. New York: ONU, 2001. Disponível em: $<$ http://www.un.org/esa/sustdev/sdissues/technology/ emaportuguese.pdf $>$. Acesso em: 01 abr. 2005. PERRINI, F; POGUTZ, S.; TENCATI, A. Corporate social responsability in Italy: state of the art. Journal of Business Strategies, v. 23, n. 1, p. 65, Spring 2006. 
PORTER, M. E.; VAN DER LINDE, C. Green and competitive: breaking the stalemate. Harvard Business Review, v. 73, n. 5, p. 120-134, Set./Oct. 1995a. Toward a new conception of the environment-competitivenes relationship. Journal of Economic Perspectives, v. 9, n. 4, p. 97-118, Fall 1995b. RAUPP, E. H. Desenvolvimento sustentável: a contabilidade num contexto de responsabilidade social de cidadania e de meio ambiente. Revista de Contabilidade do CRC - SP, São Paulo, n. 20, ano VI, jun. 2002.

RAAR, J. Environmental initiatives: toward triple-bottom line reporting. Corporate Comunications, v. 7, n. 3, p. 169, 2002.

RIBEIRO, M. S. Contabilidade ambiental. São Paulo: Saraiva, 2005.

RICHARDSON, R. J. Pesquisa social: métodos e técnicas. 3. ed. São Paulo: Atlas, 1999.

ROGERS, G.; KRISTOF, J. Reducing operation and product costs through environmental accounting. Environmental Quality Management, v. 12, n. 3, Spring 2003.

SALING, P. et al. Eco-efficiency analysis by Basf: the method. International Journal of Life Cycle Assessment, ABI/INFORM Global, v. 7, n. 4, p. 203-18, 2002. SCHMIDHEINY, S. Eco-effciciency and sustainable development. Risk Management, ABI/INFORM Global, v. 43, n. 7, p. 51, jul. 1996.

STANKO, B. B. et al. Environmental accounting. Business and Economic Review, v. 52, n. 3, Apr./June 2006. SOUZA, V.; RIBEIRO, M. Aplicação da contabilidade ambiental na indústria madeireira. Revista Contabilidade e Finanças, n. 35, p. 54-76, maio/ago. 2004.

SUSTAINABLE MEASURES. What is an indicator of sustainability? West Hartford: Susteinable Measures, 2006. Disponível em: <http://www.sustainablemeasures. com/Indicators/WhatIs.html $>$. Acesso em: 09 mar. 2006. GEORGINA, W.; THOMAS J JR, P. Cleaning up our act: accounting for environmental liabilities. Business Credit, v. 96, n. 7, Jul./Aug. 1994.
UN, UNITED NATIONS. Environmental management accounting: procedures and principles. United Nations Division for Sustainable Development. United Nations, New York, 2001. Disponível em: <http://www.un.org/ esa/sustdev/publications/proceduresandprinciples.pdf $>$. Acesso em: 01 abr. 2005.

VALLE, C. E. Como se preparar para as Normas ISO 14000: qualidade ambiental: o desafio de ser competitivo protegendo o meio ambiente. 3. ed. São Paulo: Pioneira, 2000.

VELASCO, R.; MOORI, R. G.; POPADIUK, S..

Evaluation of management environmental systems: the brasilian case. Science Research Network, Working Paper Series, 2001.

VELLANI, C. L. Passivo ambiental e a ecoeficiência. Facef Pesquisa, v. 11, n. 3, Set./Dez. 2008. ; RIBEIRO, M. S. A contabilidade e a

sustentabilidade. In: SIMPÓSIO DE ADMINISTRAÇÃO DA PRODUÇÃO, LOGÍSTICA E OPERAÇÕES

INTERNACIONAIS, 9., São Paulo, 2006. Anais... São Paulo: Fundação Getúlio Vargas-SP, 2006. ; NAKAO, S. H.; RIBEIRO, M. S. A avaliação de programas ambientais e a contabilidade. In: CONGRESSO BRASILEIRO DE CUSTOS, 11, 2004, Porto Seguro. Anais... Porto Seguro: Associação Brasileira de Custos, 2004.

; NAKAO, S. H. Investimentos ambientais e redução de custos. In: CONGRESSO USP DE CONTABILIDADE E CONTROLADORIA, 3., 2003, São Paulo. Anais... São Paulo: Departamento de Contabilidade e Atuária da FEA/USP, 2003.

WBCSD, The World Business Council for Sustainable Development. Eco-efficiency Leadership for Improved Economic and Environmental Performance. Geneva: WBCSD, 1996.

YIN, R. K. Estudo de caso: planejamento e métodos. Tradução Daniel Grassi. 3. ed. Porto Alegre: Bookman, 2005. 